\title{
Alternative Fuel And Energy Production In Aruba: A Case Study
}

Mark Meckler, Ph.D., University of Portland, USA Bill Barnes, Ph.D, University of Portland, USA

\begin{abstract}
On the island of Aruba, a combination of recently rising oil prices, the socio-cultural influence of the Netherlands, and a desire for a greater degree of long term autonomy are helping to increase interest in natural resource conservation and alternative fuels and energy production methods. The case begins with a citizen facing economic hardships and then paints three alternatives to reduce Aruba's dependence on oil: 1) possible biodiesel production on the island, 2) the Master Engineer for the country working through negotiations for a wind power "farm" on the island, and 3) the Master Engineer working with the hotel consortium on a plan to air condition Aruba's hotels using sea water air conditioning (SWAC). In all situations, we are faced with the uncertainty and the challenges involved in cleaner technology implementation.
\end{abstract}

Keywords: Alternative Fuel and Energy Production in Aruba; Energy Policy in Aruba; Business Case Study of Aruba

\section{LIFE ON THE ISLAND}

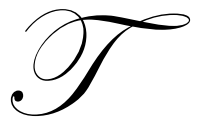

he family was together on Aruba for New Year, and Astrid Cruz complained, again, that the truck did not come to pick up the overflowing garbage. It had taken an irate telephone call two days before Christmas to have them empty the giant trash can in front of the house before the next wave of holiday-sized trash flowed out for New Year. Because the public trash utility service was undependable, Astrid was paying Afl.50 per month extra to have a private company haul and dispose of her trash.

There was more rain in Aruba this year than anyone in the family could remember. The garden was flooded with water for the first couple of weeks in December. It poured rain every day, squalling across the Caribbean desert landscape. It was miserable for the Arubans. Many would not go to work when it rained. Common wisdom was when it rains: stay in the house.

Even with all the rain, the price of water continued to skyrocket. It really only rains in December, and local homes long ago stopped collecting the run-off in cisterns. Due to the expense, people weren't keeping farm animals any more. Just giving water to the few sheep and geese in the back yard each day was beginning to create more expense than the value of raising them.

Water was so expensive on Aruba because it was processed from seawater using reverse osmosis desalination. Aruba's water plants were multi-flash evaporator plants. There were eight light plants with a total production capacity of $42.000 \mathrm{~m}^{3}$ per day. This is enough water (used at normal rates) for a population of about 150,000 . The seawater had 36,000 particles pre million ( $\mathrm{ppm}$ ), which is reduced in the water plants down to 10-20 $\mathrm{ppm}$. After processing, the brine byproduct of the water plants went back to the sea.

The water desalinization plant was run with refined petroleum and heavy diesel oil fuel (\#6). Oil of all kinds was getting very expensive. In early 2008 , the price of crude oil hit $\$ 148$ per barrel. At a fixed exchange rate of 1.78 Aruban Florins (AFl.) per U.S dollar, that's AFl 263 per barrel. 
Basic needs on the island were also rising in price. Just filling the small Nisan Sunny with gas cost 80 Florins, and salaries were not keeping up with the rise in the prices. Despite a string of record-breaking tourism income years, life on the island of Aruba was somehow getting harder instead of easier.

Entrepreneurs on the island had not yet stepped in to solve these problems. Entrepreneurship was common in Aruba, and yet few entrepreneurs specialized in conservation, efficiency and green products and services. Despite the huge amounts of waste oil generated by the hotels and restaurant, no one was producing or selling biodiesel. Despite 325 hot and sunny days per year, solar panels were extremely rare. Despite famous, consistent and predictable winds, wind power was almost non-existent.

Arubans were not yet significantly concerned about global warming and its effects, despite being a small island country. And Arubans were certainly not concerned about global pollution. The sky and water sure looked clean to them. Arubans were also not yet concerned that much about prices: most people had a good job, and could afford a bit more for food and other goods. They tended to blame the high prices on the government, and complained through the newspapers for "them" to do something about it.

For the last 20 years, the economy was good when tourism was good; and tourism was good. But somehow the economy was not as good as it should have been. With all that foreign money flowing in, how was it going out so fast? How could the government be strapped for cash?

Also, increased tourism sometimes seemed to be at the expense of the environment. Tourists brought money but they also brought pollution and took up space that used to belong to everyone. The beaches were still beautiful, but some of them weren't quite as perfect as they used to be. Some beaches near the "high rise" hotels were starting to get a lot of seaweed beds growing up. People did not want to swim in that.

Tourism and jobs and prosperity seemed to bring other problems as well. There were too many cars and there was terrible congestion on the roads. Between the tourists driving the rental cars, taxi drivers, tour buses, delivery trucks and locals driving their own cars, the roads were packed. There were over 85,000 vehicles with an official population of just under 110,000. In Holland, the nation of which Aruba is a province, people preferred bicycles. Aruba is just as flat as Holland, but there were no bike lanes, and biking was dangerous. Everyone drove a car.

With the conservative MEP dominated government and parliament, radical or architectural change projects had very low success rates. The public water and electric utility "WEB" owned the water and electricity generation, storage and delivery assets and rights for the entire island of Aruba. The government controlled WEB through leadership placements. If WEB did not advocate and cooperate fully, a project would not go forward. Proposals to help with energy costs and consumption that were not considered "competence enhancing" had never passed. Many innovations related to sustainable energy use were well researched, fastidiously designed and professionally bid-out. However, only competence enhancing innovations moved forward, such as WEB's new high yield diesel generator.

As Astrid contemplated future life on the island, she realized she was a bit uneasy - it was something she couldn't really put into words. Was it a sense of better days gone by and an age of austerity - or of new possibilities?

\section{Petroleum Ubiquity on One Happy Island}

As in any country, fuel technology on the island evolved significantly over time. The Arawak ancestors used dried dung and watapana wood chips for their cook fires. Aruba has always been warm, and so has not needed fuel for heating buildings. In the first half of the 20th century, windmills that the Dutch brought here were widely used to pump water. Some people used windmills for electricity, but it was rare. Captain Don ${ }^{1}$ over in Bonaire lived out in the kunuku${ }^{2}$, where there were no phone or electricity lines, so he collected old car batteries and hooked them up to a windmill and ran his house on DC like a car or a boat.

\footnotetext{
${ }^{1}$ Don Stewart, founder of the Scuba diving resort Habitat, is famously known in Bonaire, Netherlands Antilles as 'Captain Don.'

2 Kunuku is the Papiamento word for "out in the bush." 
Over time in Aruba, oil became king. Everything ran on oil: transportation, electricity, and even drinking water were completely dependent upon a steady and affordable supply of oil. They even burned oil to make fresh water at WEBs reverse ionization desalination plant in Balashi.

Lago was the first oil refinery. It became really big during middle years of the World War Two. The whole southwest shore became industrialized and San Nicolas became a boom-town. The crude oil came from Venezuela and the workers from all over the Caribbean. With all the refined oil, Arubans didn't really need to use windmills to produce electricity anymore or to run water pumps, and pretty soon the windmills disappeared.

Lago closed in the 1980's, and a lot of people lost their jobs. The economy struggled for a while, but then Botico Cruz got Aruba "status apart" ${ }^{33}$ and changed the island's focus to tourism. Coastal Oil Company ${ }^{4}$ came to town some years later, but it was never the same amount of jobs as when Lago ran the place. In 2004, Coastal sold the refinery to Valero Oil Corporation ${ }^{5}$. Aruba was home to a few competing fuel retailers and one major fuel producer. Texaco, Shell and Valero were the major retailers, and Valero owned and operated a large oil refinery on the southeast coast of the 4 by 28 mile island. Valero produced gasoline, diesel and other products for export, and shared the local consumer market with Texaco, Exxon and Shell.

Biodiesel was not offered anywhere on the island. Biodiesel gas was getting popular in the Netherlands, but somehow, nobody had ventured into this business in Aruba. Two primary biodiesel products were gaining a market around the world. One product was $20 \%$ of biodiesel added to regular diesel to make B20, a 20/80 mix of biodiesel/ diesel. This was easy fuel for regular diesel engines to use - no adjustments were necessary. B100 is $100 \%$ biodiesel. Regular diesel prices had shot up lately, even higher than gasoline prices. The cost per barrel of crude oil was about 108 USD.

Older diesel engines need a bit of modification to take B100. The costs of modifications were uncertain, and experts to do the work were nowhere to be found. These factors raised serious questions about the market for bio-diesel in Aruba and how demand might be stimulated.

The beauty of bio-diesel is that its main raw material input is vegetable oils. Biodiesel is made through a chemical process called transesterification whereby the glycerin is separated from the fat or vegetable oil. The process leaves behind two products -- methyl esters (the chemical name for biodiesel) and glycerin (a valuable byproduct usually sold to be used in soaps and other products). You can often get these oils easily in the form of used cooking oil.

In many countries, like in Aruba, there are a host of restaurants and other businesses that need to dispose of the very materials that are inputs to making biodiesel. In most places, business paid other businesses to pick it up and dispose of their waste oils, organic waste. At 75\% occupancy, an average major beach resort on Aruba disposes of about 20 gallons of deep fryer oil per day, and 100 to 200 pounds of organic food and beverage waste per day. The human waste, around 10 gallons per occupied guest room per night, is carefully processed for the cleaned waste water that is stored and pumped for use in gardens and on golf courses.

\footnotetext{
3 "Status Apart" is the term used for Aruba's political relationship with The Netherlands and the Netherlands Antilles. Aruba had been a member of the Netherlands Antilles, governed from Curacao. In the 1980's, Botico Cruz led Aruba to independence from the Netherlands Antilles so they could be self governing, though still part of the Netherlands.

${ }^{4}$ Coastal Oil Company is/was owned/operated by Houston oilman Oscar Sherman Wyatt Jr,, with headquarters in Corpus Christi Texas. Coastal Oil also has a Houston office in Houston Texas.

${ }^{5}$ Valero Energy Corporation based in San Antonio Texas and is the largest refiner in North America.

C) 2012 The Clute Institute http://www.cluteinstitute.com/ 




Figure 1

Source: http://www.biodiesel.org/pdf files/fuelfactsheets/Production.pdf

State of the art technology could recover energy from organic based oil inputs at a rate of about $45 \%$ as bio-diesel output. State of the art recovery of biodiesel from unsorted organic garbage yielded about a gallon of biodiesel per 100 pounds of organic waste. On Aruba, the 20 or so major hotels put out enough oil and waste to make roughly 175 gallons biodiesel per day. The transportation department would have had enough fuel to power all of the island's public bus routes for one day. That's not exactly a lot of fuel, but 175 gallons of diesel per day still helps, and it would divert all of that waste that normally went straight to landfill.

Biodiesel definitely had some appeal. First, biodiesel could help communities become less dependent on non-renewable fossil fuels that would eventually run out. Second, biodiesel was more efficient than gasoline vehicles running on biodiesel or diesel can get roughly $30 \%$ better mileage per gallon. Finally, biodiesel could "close the carbon loop" if it was sourced from crops that would be grown over and over, re-sinking the equivalent carbon that was emitted when the biodiesel was burned.

Biodiesel also had some general problems in places where it was produced. One problem is that it often took a lot of energy to produce it, including the energy to make the original vegetable oil. Even worse, as demand for bio-diesel outstripped waste/recycling related inputs, corporations around the world were resorting to planting crops specifically to be turned into bio-diesel. Depending on how the crops were grown, this could be energy inefficient and land inefficient.

In the developing countries this problem had become acute, and had become connected to food. Large corporations frequently enticed populations into replacing their food crops into crops for fuel. Unfortunately, this was beginning to result in shortages of food and hence higher prices.

Another general problem was that biodiesel consumption produced a lot of soot, a known cancer-causing pollutant. In less ventilated and more urban geographies, diesel soot was considered a major public heath problem. In Aruba where trade winds blew the soot right off the island, people didn't really care much about soot.

Biodiesel was certainly an option for the island, and there were a few entrepreneurs already beginning to evaluate the possibilities. One already had business plan for "Petroleum Ubiquity." But there were many questions. Did it make economic sense? Was biodiesel environmentally sound enough for Aruba? Was it worth the opportunity cost - what were some of the other options for fuels and other clean technologies? What if everyone drove hybrid electric cars or the natural gas cars they were selling in California? What about wind, or solar or another project? 


\section{Winds of Change}

Leon Hamers, The master engineer ${ }^{6}$ (the M.E) for Aruba and for the $\mathrm{WEB}^{7}$ (the electric and water utility) had just met with Vestas Wind Systems A/S's representatives for the final time before the next year's budget was due. The Vestas reps had made a great pitch, proposing 7 windmills on a windswept hill on the east side of Aruba. This plan was later modified for a $15 \mathrm{MW}$ wind park, 10 windmills of 1,5MW each, located at Vader Piet where the wind from the seas was almost perpendicular to the shoreline. The average wind speed at the hub height of 65 meters was around 10 meters/sec. The expected capacity factor for the wind generators was around $60 \%$. These windmills would provide more than enough power for the entire town of Santa Cruz and much of the surrounding Kunuku. $^{8}$

Working with the company was appealing. Vestas, headquartered in Randers, Denmark, was one of the world's largest windmill manufacturers. Given Aruba's long ties to the Netherlands, cultural objections were not a factor, and NIMBY problems were unlikely. ${ }^{9}$

But Hamers was hamstrung by the budget. It seemed that the cost of tying the windmill farm into the island's electricity grid was just too expensive. However, he was still unsure if he had really counted all of the potential benefits, and was having trouble sorting out all of the considerations.

The master engineer wanted to be a part of a move toward renewable resources, toward reducing dependency on fluctuating oil markets and other outside energy sources. Some people on the island had finally begun to realize that at least some renewable energy alternatives were possible and promising. The recent spikes in oil price helped bring the issue to the forefront of the island's economic policy debates.

The island's water and electric utility, WEB, used oil-fired electricity generators that provide not only all electric current for the island, but also all of the potable water through a desalination process. For most countries, coal fired power plants produce a large share of the electricity, but not in Aruba. Aruba used oil. Not that the ME would have preferred coal, knowing that coal was worse for greenhouse gas and other pollution. The bottom line was that the M.E wanted to help Aruba move toward renewable energy before he retired. He had considered other renewable options like solar energy, but not as seriously as wind energy. Wind power seemed appealing because the technology was straightforward. Vestas had such a good product, and Aruba was world-famous for its consistent east wind.

The M.E was torn. He knew he needed to make a decision soon. The windmills were expensive. On the other hand, he knew that, once in place, the costs of operating the windmills were very low. The price per kilowatt hour for wind had fallen substantially from decades ago, as the Vestas reps had made clear. With the price of oil where it was, customers might benefit sooner than anyone expected. Producing energy from wind was much cleaner than oil produced energy. With the exception of a few unhappy birds, it was hard to see any other real "externality cost." Should he accept the Vestas proposal? He had done some homework on the merits and demerits of wind, but he felt like he needed to do some more before he made a decision.

\section{Going Low Tech: Seawater Air Conditioning}

Hamers had been up until 3:00 a.m. in his office doing research, and he was tired. He was struggling with Aruba's huge demand for electricity to cool the tourist hotels, and at least two more major resort hotels were being built. The hotel owner's consortium was always complaining about their utility bills. But now, with skyrocketing oil

\footnotetext{
${ }^{6}$ Names in this section have been removed or altered.

${ }^{7}$ WEB, or WATER-EN ENERGIEBEDRIJF Aruba N.V., is a public corporation owned by the Aruban government that owns and runs the electricity generation and the water desalination plant in Balashi, Aruba. WEB produces nearly 10 million gallons of water per day. The Island of Aruba has maintained a reputation for the best quality drinking water in the Caribbean.

${ }^{8}$ Santa Cruz is a medium sized town with a population of about 10,000 in the center of Aruba.

${ }^{9}$ NIMBY = Not In My Back Yard. Wind mills around the world are often faced with stiff objections by local residents, who often protest the health effects of windmills due to "shadow flicker," noise, aesthetic concerns, or other concerns.
}

(C) 2012 The Clute Institute http://www.cluteinstitute.com/ 
prices, their bills had spiked up dramatically, and the M.E felt sympathy for their plight. WEB, the government owned water and electric utility that he had designed had no choice but to pass the increased expenses on to their customers. That meant the hotels had to either cut other costs or pass their increased expenses along to the tourists. The danger for this tiny island was that tourists were very price sensitive, and if hotels had to charge more, tourists might go elsewhere and the island's economy, so dependent upon tourism, could crash. The prime minister had not yet chimed in on the matter, but the M.E knew that the island's absolute dependence upon oil was now a precarious position, and would likely be a major political issue in the next election.

A few years back the M.E had consulted with the Government of nearby Curacao on a project tapping into the Caribbean Sea to cool the island airport. At the time, he imagined a much larger scale system for Aruba, using seawater to control the climate in all of the major resort hotels. He had let the idea gestate; it was something he would revisit as an entertaining engineering puzzle more than a real innovation project. Back then, when he first had the idea, the price of oil was pretty low, and utility bills were reasonable, and there was a moratorium on any new resort hotels. Somehow, however, that moratorium had been ignored, and oil prices had risen steadily. So, for the past four months, he had begun a serious investigation into the technology and the economics of a large-scale oceanpowered central cooling plant. Taking the resort's air conditioners off of the overloaded electric grid was a problem he wanted to solve as soon as possible.

His research project kept him up late for a lot more work than he had anticipated. There were a lot of considerations. Hydro-thermal conversion technology for electricity was still in its infancy, inefficient and expensive. However, using cold seawater directly to cool rooms - that was relatively low-tech, and seemed like something Aruba could do. The M.E knew for a fact that Curacao had drastically lowered its use of electricity in the airport.

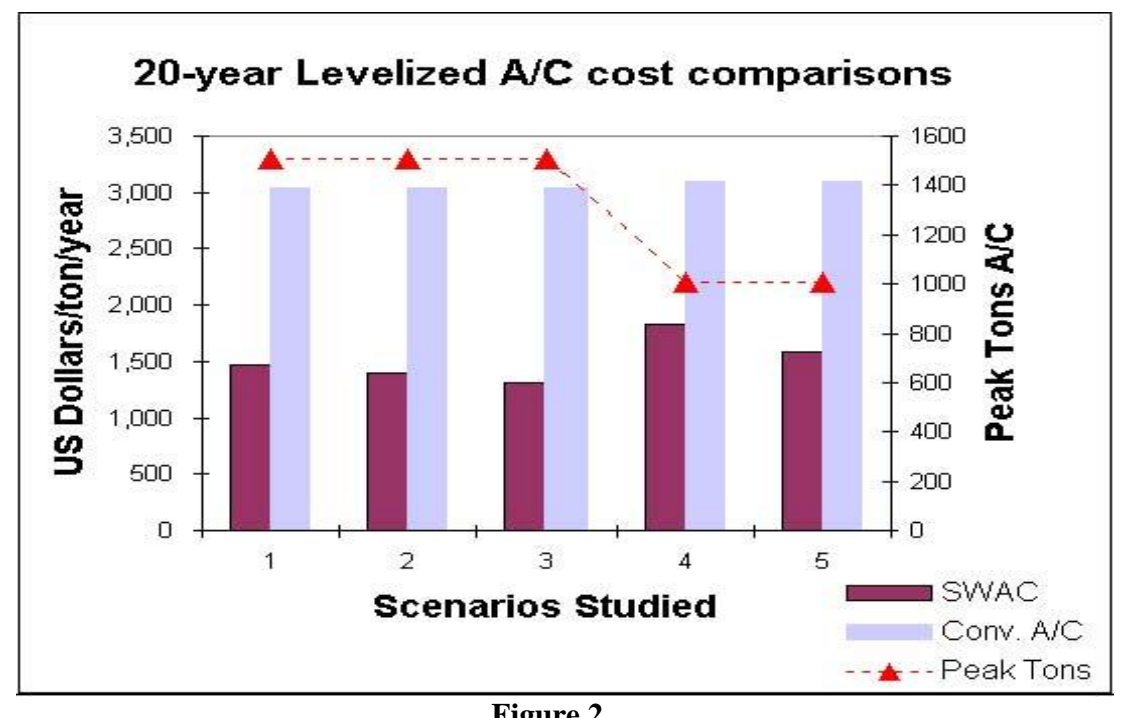

Figure 2

Source: http://www.makai.com/renewable_energy/swac.htm

Figure 2 above shows an economic comparison between seawater air conditional and conventional air conditioning for the airport in Curacao, Netherlands Antilles. Construction and operating costs, circa 2000 and projected over the life of each system are included in the comparison along with system performance under varying load conditions. Including all capital and operational costs, the study concluded that SWAC cost one-half that of conventional air conditioning.

Figure 3 below shows the main components of a seawater air conditioning system: a seawater supply system, a heat exchanger (cooling station) and a closed-loop chilled water distribution system. A series of pumps originating in a 
cold water sea current push seawater to a heat exchanger. The temperature of the arriving seawater is lower than the temperature maintained in the chilled water loop. When seawater passes through the heat exchangers, pulls heat from the chilled water loop, (keeping it chilled) and is then returned to the ocean. It is important that the warmer return seawater is dispensed into deep water well away from temperature sensitive ecosystems such as coral reefs. Therefore, two major pipelines are needed: one bringing the cold sea water in to the cooling station on or near land, and one returning the warmer seawater out into the open sea.

The chilled water loop runs from the cooling station through hotels and other large buildings with conventional air conditioning systems for heat removal. As the chilled water moves through each building and absorbs heat, its temperature rises from an incoming value of perhaps $60^{\circ} \mathrm{F}$ (in Aruba's case) to an outflow value approximately $69^{\circ} \mathrm{F}$. This return, somewhat warmer chilled water then re-enters the heat exchanger, where new seawater cools the re-circulating fresh water. One of the major advantages of seawater air conditioning is that it can make use of existing infrastructure within most buildings. That is, hotels using the seawater air conditioning system are identical internally to buildings cooled with conventional air conditioning.

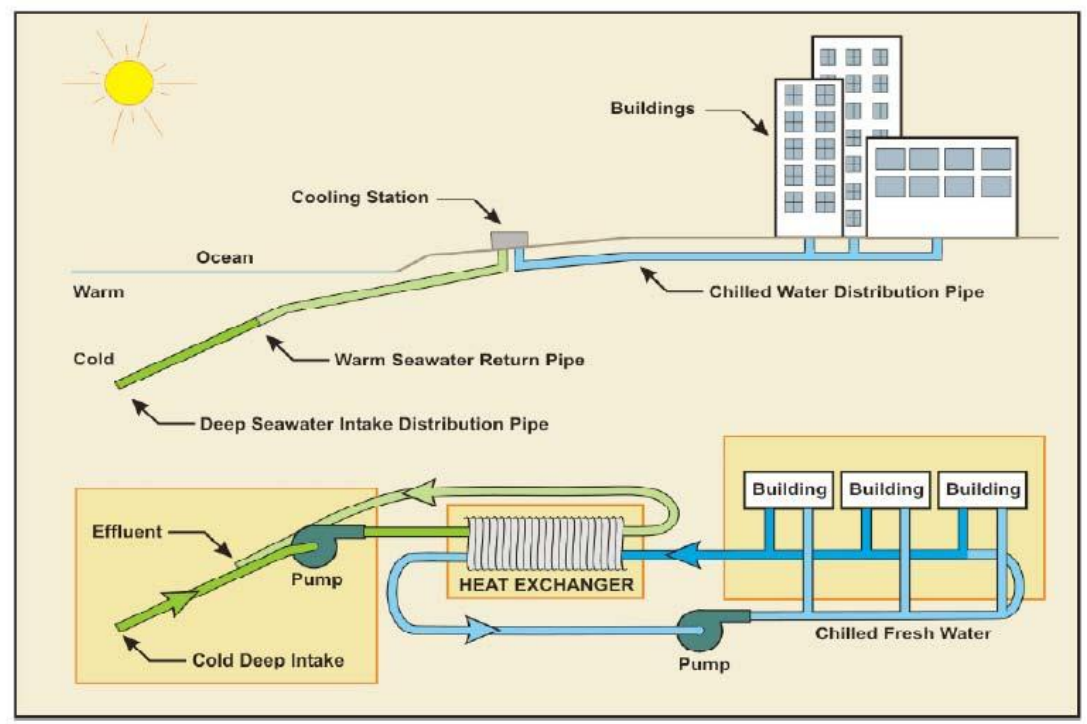

Figure 3

Source: Guam Power Authority

The M.E knew that Aruba had no shortage of cold seawater. The renewable source was just three miles offshore. Furthermore, just three miles offshore ran a reliable current of relatively cold seawater. Vast and appealing, cold sea water was right outside his office door - stretching as far as he could see. This seemed like a possible solution for the resort's climate control difficulties, but not one that would reduce Aruba's dependence on oil for electricity and drinking water. With a limited budget for major capital project, was this a better project than pursuing wind power? change.

Oil had just hit US\$138 per barrel. Aruba was highly dependent upon oil - too dependent. Something had to 


\section{CASE TEACHING NOTES}

\section{Teaching Objectives}

This case is suited for environmental economics and strategic management of technology related courses. The case involves a confluence of factors that are common in business decisions, including the environmental impacts and pollution externalities, economic costs, technological innovation, social inertia, and operant social values (as opposed to espoused social values). The three scenarios are purposely open-ended, and are intended to introduce students to the challenges and opaqueness involved in new clean technology adoption. Other issues that play a large role in the analysis are systems theory, disruptive vs. sustaining innovation, path dependencies, complimentary technologies and complimentary assets, and the struggle to provide a unique value proposition for customers.

A central theme threaded through all three scenarios involves the viability of a clean technology, and the cases are an excellent way to motivate the notion of clean technology (CT) as defined by Eban Goodstein (2011) and others. If used in an environmental economics course, by the end of the exercise, students will have evaluated whether the technologies generate similar services relative to the older technology, whether it has long run private marginal costs that are comparable to existing technologies, and whether the technology is in fact less environmentally destructive. If defined as a CT, students will also evaluate market and government obstacles to promotion and how to overcome them.

The case also serves as an excellent device for going through White's (1978) criteria for effective innovation and for identifying network externalities that significantly impact industrial formation around a new technology. (Michael Porter recently included network externalities in his famous "5-forces analysis" as a sixth force).

We very strongly suggest some sort of preparatory reading on systems theory. Most academic library systems have a copy of John van Gigch's "Systems Design Modeling and Metamodeling" (Plenum Press, 1991). Have students, especially MBA's, read chapter two "The Systems Approach", (and chapter one if you see fit). We also strongly suggest a primer on energy economics and policy. Good sources include Ch 18, "Promoting Clean Technology: Theory" and Ch 19 "Energy Policy and the Environment" in Eban Goodstein's text, Economics and the Environment.

\section{Supporting Readings:}

- $\quad$ Any strategic management chapter on environmental analysis (We happen to use Hill and Jones)

- Goodstein, E. (2011). Economics and the Environment. Hoboken, NJ: Wiley and Sons.

Ch 18, "Promoting Clean Technology: Theory"

Ch 19, "Energy Policy and the Environment"

- $\quad$ Porter, M. (1996). What is Strategy? Harvard Business Review. 74(6): 61-78.

- White, G. (1978). Management Criteria for Effective Innovation. Technology Review. 56: 15-23.

- $\quad$ Kerr, 1975, On The Folly of Hoping for A while Rewarding B. Academy of Management Journal. 18: 769783.

- $\quad$ Rumelt, R. (1980). The Evaluation of Business Strategy, in WF Glueck, Business Policy and Strategic Management, 3rd Edition. New York, NY: McGraw-Hill.

\section{Advanced Readers (more appropriate for MBA students)}

- Van Gigch, J. (1991). System Design Modeling and Metamodeling. Chapter 2, The Systems Approach. New York: Plenum Press.

- $\quad$ Arthur, B. (1988). Competing technologies: An overview, in: Dosi et al. Atkinson, AB and JE Stiglitz, A new view of technological change. Economic Journal, 79 (3) 573-578.

- Christensen, C.M., Suarez, F. and J.M. Utterback (1998). Strategies for Survival in Fast-Changing Industries. Management Science, 44(12) S207-S220.

- $\quad$ Teece, D. (1986). Profiting from Technological Innovation. Research Policy, 15: 285-305.

- $\quad$ Abernathy, W. \& Utterback, J. (1978) Patterns of Industrial Innovation. Technology Review, 80 (7) 40-47. 
- Lieberman, M. \& Montgomery, D. First-Mover (Dis)Advantages: retrospective and Link with the Resource-Based View. Strategic Management Journal, 19: 1111-1125.

- Chistensen, C. \& Bower, J. (1996) Customer Power, Strategic Investment and the Failure of Leading Firms.Strategic Management Journal, 17 (3) 197-218.

\section{Intended Courses and Levels}

Intended courses include Environmental Economics, which typically assumes exposure to introductory microeconomics, and courses in Management of Technology and Innovation. This case would be appropriate in the middle of these courses, after students have had exposure to topics such as network externalities (including pollution externalities), complimentary goods, dominant designs, cost benefit analysis, technology adoption and diffusion cycles, and environmental regulation and policy. The case is particularly useful in environmental economics when the course turns from command and control regulation and begins discussing alternative, market based approaches to environmental cleanup. The case is particularly useful in management of technology and innovation courses while the topics of path dependency, dominant design and timing of entry are discussed.

\section{Discussion and Homework Questions}

1. For each scenario, what are the most critical issues for the decision maker? Try to come up with at least four, and rank them in order of importance.

2. What kind of information do you need to actually resolve your top two issues? Is it qualitatively based, or quantitative? Do you have it now? If not, is it possible to get it? Do some research and try to find some of this information. Bring it to class.

3. Read Eban Goodstein's (2011) definition of Clean Technology, (Ch 18). Using Goodstein's criteria, do these technologies pass as clean technology? Which of the three possible clean technology scenarios is most appealing in terms of overall environmental impact?

4. $\quad$ Read the first four pagers of White's (1978) article "Management Criteria for Effective Innovation." After considering his criteria, which of the three technology scenarios is most appealing? Why?

5. Do the results of evaluating using White's criteria differ from the results using Goodstein criteria? Explain why or why not.

\section{Answers to Discussion Questions}

Question 1. For each scenario, what are the most critical issues for the decision maker? Try to come up with at least four, and rank them in order of importance.

Student answers will vary. The following might be a representative sample of possible answers, with a relative ranking at the end.

\section{Scenario I.}

Issues: Is it the right time for a biodiesel "launch" on the island? (is there a market?) How do Arubans feel about the idea of "green" diesel - is this the way to position the product? Is there adequate input supply (veggie oil)? Is that supply reliable? If initially successful, would it attract competition (how big are the barriers to entry?) Is biodiesel easily made and the equipment easily maintained? Is it equivalent to extant fuel alternatives in terms of quality? Will biodiesel actually help to improve the environment? Is biodiesel cost competitive in the long run? Are there better green transportation alternatives, such as natural gas cars, regular gas coupled with hybrid cars, or mass transportation? Will the government help out - are there any incentives that are available for green businesses? 
The rankings may vary based on a student's orientation - some students will put environmental concerns at the top of their list; others will put profitability and concerns related to viability of the business at the top. From an environmental perspective, if biodiesel is in fact not environmentally superior, then it would not make sense to create a business, even if successful. This is a good time to point out that sustainability oriented entrepreneurs may be driven by environmental concerns (so the business is a means to an end), or by making a profit (and the green product is a means to an end), or both. In this first scenario there are clear hints that this decision maker is motivated by environmental concerns. This is also a good opportunity to explain the concept of market failure: profit maximizing suppliers and utility maximizing demanders interacting in a market may not come up with the "socially optimal" solution. It is up to consumers, businesses, and government to collectively determine what a socially optimal point is. If it involves a cleaner environment and the market is predisposed to dirty oil and gas, then government incentives may be useful and necessary (and should be weighted accordingly).

\section{Scenario II.}

Issues: Is Vestas a reliable company, with the best product for the money? What is the short run (fixed) cost to buy the windmills? What's the long run cost to produce electricity, relative to other alternatives? How hard is it to connect to and utilize the existing electricity grid? How dirty is the existing technology now that produces electricity, compared to wind-power? Is wind the way to go - are there other appealing alternative energy scenarios on the island? Would there be any kind of environmental problem associated with wind? Who would oppose the project? Who are the winners in this project? What happens when the wind is not blowing?

Again rankings vary, and they might be similar to the rankings above based on the same reasons. Students instinctively know that windpower is cleaner for many pollutants, and therefore may not rank this as an issue. With wind in general, the environmental question is not completely settled. However, there is enough information in this scenario to argue that common concerns, such as the "not in my backyard" problem, have been addressed. Therefore the more important issues revolve around cost competitiveness relative to other technologies. This would include the feasibility and the cost of connecting to the grid, and not just the cost of the turbines. The ultimate cost to the consumer is very important here as well; will utility prices go down, stay the same, or go up? Additionally, the "intermittent" nature of wind is a major consideration, and this is distinctly different than oil fired electricity plant, which can be fired continuously.

\section{Scenario III.}

Issues: Is this technology developed enough, or is it too speculative? Can I easily get it and set it up? How reliable is the technology? What are the costs of installing? What are the costs of maintaining? What are the long run costs? Are there any environmental costs? Can seawater air conditioning be used for other applications, or is this just specific to the hotels?

Like Scenario I, this scenario clearly involves technology that is relatively young. The system takes the hotels "off the grid" for at least some air conditioning functions, so positive environmental impact on that front should be fairly clear: less $\mathrm{CO} 2$ emission. There is no clear hint about any negative environmental impact of the piping system, but it may still exist. The main concern here should be the reliability of the technology.

Question 2. What kind of information do you need to actually resolve your top two issues? Is it qualitatively based, or quantitative? Do you have it now? If not, is it possible to get it? Do some research and try to find some of this information. Bring it to class.

For all scenarios, if a top issue involves economic calculation, then students will want to try to find quantitative information. All three scenarios could use more numbers - Scenario III comes closest, with a cost estimate of a project involving similar technology. Some very useful information can be obtained in the public arena that will help to very roughly guesstimate future long run expenses. For example, the price per kilowatt hour of wind power is widely available - around 4 to 5 cents, which can serve as start for evaluating competitiveness. However, much more information is needed for the 3 scenarios. In the case of wind, the cost of connecting to this particular grid is an obvious concern. Make sure to note to the students that "internalizing externalities" (pricing, for example, the 
true cost of oil fired electricity) can be quantitative, but that it is extremely difficult to do. Environmental analysis is also often quantitatively based, not necessarily in monetary terms. Qualitative information is also extremely important: for example, information about similar technology implementation experiences and the constraints faced.

Question 3. Using Goodstein's (2011) three characteristics for clean technology, do these options pass as clean technology? Which of the three possible clean technology scenarios is most appealing in terms of overall environmental impact?

The technology generates services of similar quality to existing technologies.

Biodiesel: yes, although diesel engines are quite different than gas engines. Also, compared to regular diesel, biodiesel actually extends the life of an engine, although pure biodiesel may degrade older rubber fittings and hoses in old engines (thus a relatively inexpensive retrofit is required).

Wind: yes, although this is only the case when the wind is blowing. So this is a critical issue. Wind power is more intermittent than non-renewable power production, because wind can dissipate. Thus, there has to be a backup for any wind system, and this is understood at the start.

Air conditioning: probably, as far as can be determined.

The technology has minimum long run private marginal costs comparable to existing technologies.

This hinges on having some sense of the numbers, which can be derived at least in part through research online. None of the scenarios stand out as being overly expensive relative to the current options. Biodiesel does not need large scale for this to be the case; neither does seawater air conditioning (these are known as small scale CTs). Wind, on the other hand, is becoming competitive in part because of the much greater scale of production occurring (driving down the price of the technology) and the increasing efficiency (and size) of the windmills themselves. Furthermore, windmill design has improved the ability to capture much lighter winds.

The technology is environmentally less destructive than existing technologies.

This is arguably the biggest question, for "clean" technology.

Biodiesel suffers from the adding up problem, in the sense that it clearly lowers greenhouse gasses, but raises soot and some other pollutants relative to gas. Important to note here is that this is in tandem with extant diesel engine technology, which has lagged gas cars in terms of pollutant filtration, etc. These engines are becoming rapidly cleaner, but have some way to go. So the answer here is yes, if we are worried about global warming. Maybe not, for the meantime, if we are worried about elevated smog in our cities. In Aruba's case the winds are strong, which may blow much of the pollutants out to sea.

Wind is clearly cleaner than many other energy alternatives. The main critiques have been noise, bird and bat death, and ugly views. In terms of emissions, there really are none, so wind is very appealing on this score.

The seawater air conditioning system gets us off a dirty electricity grid (maybe soon to be cleaner, if wind were adopted). Issues here might involve fish or small animal life being sucked into the uptake tubes or somehow disturbed by the tubing system. Other than this, the impact seems minimal.

Answer: All 3 would be probably be defined as CTs using Goodstein's definition.

Which of the three possible clean technology scenarios is most appealing in terms of overall environmental impact? 
Installing 7 large windmills, each of which can power 300 houses, probably has a larger positive environmental impact than a single biodiesel gas station, or hotel air conditioning, although this depends on exactly how many hotels are involved. Also important might be the consideration of whether or not these technologies will diffuse completely across the island. In the case of wind, this is feasible over time, and getting off the grid through sea water air conditioning at the hotels would then be moot (because the air conditioning would be through clean energy).

Note that what is environmentally appealing is not the same thing as what is economically appealing. If the seawater air conditioning numbers can be confirmed (reducing air conditioning costs by half in the long run), this technology is very appealing simply as a cost saver. Wind power costs are usually about equal to or slightly more than other carbon intensive alternatives. To the extent that oil prices rise, however, wind power is increasingly attractive.

Question 4. Read the first four pages of White's (1978) article "Management Criteria for Effective Innovation." After considering his criteria, which of the three technology scenarios is most appealing? Why?

See White's criteria below for reference. It is important to go through an example with students prior to this assignment to demonstrate how to apply. Goodstein's criteria are geared toward the promotion, implementation, and long run maintenance of clean technology, and the environment is explicitly in the evaluation process. The focus of White's criteria is really "effective innovation," and the environment is tangential. This exercise can be very usefully applied, however, and different "steps" will be more applicable than others. For example, going through Step 3 for windpower will draw a student into a careful consideration of the displacement that might occur if windpower substitutes for oil powered electricity, the new jobs and other benefits created by the wind technology, and the new supporting technologies that windmills require.

Question 5. Do the results of evaluating using White's Criteria differ from the results using Goodstein criteria? Explain why or why not.

Technically all three of the scenarios qualify as clean technologies under Goodstein's criteria. It is not enough to determine that a technology is a CT; we need more analysis to determine whether or not the CT can be realistically implemented (are there market or government obstacles, and how do we overcome them?). Under White these issues are partially addressed, for example, in questions like "how favorable is cessation of the former practices weighed against provision of the latter?" and a judgment might be made here that one scenario if more favorable than another.

\section{Analysis}

As indicated above, to analyze this case, first we use Goodstein's Characteristics for Clean Technology to evaluate clean technology viability. Second we use White's (1978) criteria to evaluate innovation effectiveness. These two conceptual exercises are included below.

Summary of Goodstein's Definition of Clean Technology

Adapted from Goodstein (2011) "Promoting Clean Technology: Theory" in Economics and the Environment.

1. The technology generates services of similar quality to existing technologies.

Judgments based on quality can be difficult, and inevitably involves the subjective view of the consumer. This subjectivity matters, however, and should be taken into consideration when evaluating feasibility. For example, diesel fuel in the U.S. is still often associated with noisy, dirty engines despite improvement in modern engines. In some scenarios, the product clearly does not provide a similar service, and should be rejected as a CT on these grounds. 
2. The technology has minimum long run private marginal costs comparable to existing technologies.

This question highlights the importance of having technology available that is truly bordering on cost competitiveness with extant technology. Long run minimum private marginal costs are the costs for the firm of producing an additional unit once the technology is mature. Small-scale CTs get to this maturity relatively quickly, at low volume (low flow shower heads). Large-scale CTs involve high volume production to achieve minimum long run costs (wind power). Note that this does not call for the incorporation of externalities into the calculation; these are private marginal costs. When CTs can't compete on the basis of private costs, they have a poor survival record, even if the government tries to level the playing field and promote. Wind and solar are in a race to drive down private long run marginal costs. Although it is important to note that clean technology is better for the environment and thus represents a savings, we don't have good accounting systems yet that quantify this. Hence it makes sense to prioritize technologies that are as close to cost competitive with existing technologies as possible.

3. The technology is environmentally less destructive than existing technologies.

This is not as easy to determine as it first seems. To do this correctly, you have to account for all of the major environmental impacts of a technology, including the manufacture, use and disposal of the technology. Life cycle analysis can help to do this, and it might show, for example, that solar panel production is an environmentally damaging process, but that once panels are in operation, there is little damage. Life cycle analysis is still in its infancy, and should be seen as such. Supporting one technology or another invariably relies on a certain degree of common sense, coupled with an effort to quantify environmental impact of the product through its life cycle. Another concern is the "adding up problem," because different technologies have different environmental impacts. Gasoline consumption results in relatively high greenhouse gas emissions; for biodiesel, it is much less. But diesel consumption results in particulate matter emission (soot), and for gasoline, particulate matter is much less of a problem. To the degree that you can monetize both scenarios, the ability to pick winners increases. However, it is often very difficult to monetize scenarios like this.

Summary of White's Management Criteria for Effective Innovation

Adapted from White, G. (1978) Management Criteria for Effective Innovation. Technology Review, pp 21-28

Set 1: What fundamental technical constraints limiting the prior art are lifted?

This is the most important technical challenge, to identify the core constraints underlying previous technologies that have been lifted by the new invention and to assess the significance of looking those constraints.

What new technical constraints are inherent in the new art?

Is critical to understand the factors that limit the effectiveness of the proposed innovation. This can also help in formulating the direction of future innovations.

How favorable is relief of the former weighed against the stringencies of the latter?

It is important to keep this analysis qualitative rather than quantitative. The comparison is difficult and highly judgmental, but it can be quite meaningful.

Set 2: These questions address the actual end product(s) in which the innovation will be embodied.

Is the end product enhanced by additional technology and components required to make use of the innovation?

Will the end product be improved by including this innovation? What parts and pieces are no longer necessary? What new complimentary technologies are necessary for this to turn into a viable product? Do they exist? Are they sufficient? 
Is the inventive concept itself diluted or enhanced by the embodiment required?

When ideas are put into practice they usually have to be somewhat altered in order to fit within the current context. Sometimes the necessary changes in the initial design will limit the value of the innovation. On the other hand, sometimes the surrounding systems actually increase the value of the innovation.

Does the additional embodiment offer opportunity for further inventive enhancement? (Technology driver?)

This covers two issues. First, it addresses the balance between the value added to the end product by the innovation and the value subtracted by the requirements of the innovation. Secondly, it questions whether pursuing the embodiment of this technological innovation will compel ongoing commitment toward development of this and other supporting/complimentary technologies. This is a choice that should be made with open eyes.

Set 3: What previously emplaced business operations are now displaced or weakened by the new innovation?

There are human issues as well as resource allocation issues here that must be addressed. The power, importance, and overall psychological heath of some folks, or whole work groups, may be threatened by the new technology, and there may be unexpectedly harsh backlash if this is not recognized and dealt with in an appropriate way.

What new business operations are needed or wisely provided to support the new innovation?

Don't forget critical support areas such as purchasing/procurement, legal compliance, political lobbying, recruitment, training and development, communication systems, etc. Interdependencies can require vast amounts of capital and managerial time, expertise and support.

How favorable is cessation of the former practices weighed against provision of the latter?

This is another comparison to help make explicit whether the benefits outweigh the costs. There are some quantitative aspects of this analysis dealing with the financing of business operations, as well as a number of qualitative aspects. Unfortunately, it is hard to predict the attitudes and behaviors of people who are impacted by the change. Remember, people are not entirely (or mostly) rational, or in full control of their reactions.

Set 4: Does the product incorporating the new technology provide enhanced effectiveness in the marketplace serving the final user?

The embodied innovation should cause either increased demand in the form of either market expansion, and/or the ability to charge a higher price due to the increased value of the product from the customers' perspective. One of the three core variables in the value equation is effectiveness (qualities). The others are price and speed/responsiveness.

Does the operation reduce the cost of delivering the product or service?

Effectiveness is certainly not the only criteria. Efficiency is critical as well. Profit margins are the difference between the price that is charged and the cost of production. Either the price should go up, the cost should go down, or (preferably) both. If the answers to the first and second question in this set is no, then it is probably best to put the idea away in a file, and pull it out at a later time.

Does latent demand expansion or price elasticity expansion determine the characteristics of the new markets?

Depending upon attracting new customers by lowering the price is generally not a good idea. A relatively small drop in price requires a relatively large increase in volume just to balance out. While incremental market expansion is generally driven by price reductions, dramatic market expansion is usually driven by noticeably increased effectiveness. 


\section{Epilogue}

Oil prices in Aruba have skyrocketed. There is no biodiesel yet on the island. There is no seawater air conditioning for hotels, yet. The M.E., Leon Hammers, did ultimately approve the wind farm and the project went through as planned.

\section{RESEARCH METHODOLOGY}

Participant observation (living in Aruba for many years), several interviews, and use of available secondary literature and data.

\section{AUTHOR INFORMATION}

Mark Meckler, Ph.D., is Associate Professor of Entrepreneurship and Innovation Management at the Robert B. Pamplin Jr. School of Business Administration at the University of Portland where he teaches courses in Leadership, Strategy, Innovation and Cross Cultural Management. His current research focuses on network theories of organization and economics, regional and organizational culture, resource-based innovation strategies, and the relationship between social constructions, truth and the theories managers apply when working. He received his $\mathrm{PhD}$ from Florida Atlantic University, his MBA from Michigan State University, and his BA in philosophy from Brandeis University. E-mail: meckler@up.edu

William Barnes, $\mathrm{PhD}$, is Associate Professor of Economics and Environmental Science at the University of Portland in Portland, Oregon. His research interests include barriers and pathways to clean technology and sustainable production systems, performance outcomes associated with CSR, and comparative economic institutions. He received his PhD from the University of Notre Dame. E-mail: barnesw@ up.edu. Corresponding author.

\section{REFERENCES}

1. Van den Berg, Reimsdijk Jr., Director of Public Laboratory, Biochemistry. Government of Aruba. Interview, Dec 22, 2005.

2. Hammers, Leon. Master Engineer, WEB and Government of Aruba. Interview, Dec $29^{\text {th }}$ 2005, Jan 2, 2006.

3. Cruz, John; van Dryzen, Joseph; Iriarte, Francis; Cahinhinan, Roel and Joyce Sayama. 2004. Sea Water Air Conditioning For Tumon Bay, Guam. Retrieved from:

http://www.guampowerauthority.com/news/documents/Sea_Water_Air_Condit.pdf 
NOTES 